\title{
'Those who attack nuclear energy show a cynical denial of human ingenuity'
}

THREE Mile Island confirmed what many of us in the nuclear enterprise had suspected - that the "China Syndrome", rather then proliferation or even waste disposal, would ultimately decide the public's acceptance of nuclear energy. Nor is this unreasonable. Proliferation is an issue far from most people's perception; more than that, it faults nuclear power by association, not by intrinsic connection. As for waste disposal, despite the violent arguments, the nuclear community could always point to plausible technical solutions for wastes (one must remember that 800 years after wastes are created, their toxicity has fallen below that of the original uranium from which the wastes were created). But for the 15 billion curies contained in a 1000 megawatt reactor, we could never say that the chance of a serious accidental release was zero. Three Mile Island carried this message directly to the public; the public must decide whether it can accept this risk. Chancellor Schmidt's recent call for an international review of safety as a sequel to the International Nuclear Fuel Cycle Evaluation study of proliferation resistance is therefore most appropriate.

The fact that deaths caused by nuclear energy, are on average, considerably fewer than those estimated for most energy sources (including many solar sources if they are backed up by non-solar systems), seems to me rather beside the point. Risk as perceived by the public is not simply the product of probability and consequences - the first moment of the probability distribution of consequences. The very high moments of the distribution - very low probability high consequence events that contaminate large stretches of land - are probably more important. Thus a most important technical fix for nuclear energy would be a means of minimising the amount of land that conceivably could be contaminated in the worst possible accident. Siting reactors underground could achieve this, though at considerable expense. The recently published report on ungerground siting to the California Energy Commission concludes that comparable improvements can be achieved at much lower cost with more elaborate containment systems.

Three Mile Island suggests that even an accident that imposed an average additional radiation burden $1 \%$ of the natural background on those within 20 miles is unacceptable. For nuclear energy to survive, we must reduce the probability of any serious malfunction much below the 1 in 20,000 per reactor-year estimated in the Rasmussen report, as well as reducing any possible consequences.

Can we fix nuclear energy? I believe we can, but it will require important inst- itutional changes as well as better technology. I am therefore most enthusiastic about the plan announced earlier this year by the Tennessee Valley Authority, the largest electrical generating entity in the United States, in response to Three Mile Island. The main elements of the TVA plan are:

- the establishment of a separate operating entity with the Office of Power that is responsible only for nuclear generation;

- the establishment of an independent Nuclear Safety Review Board that reports directly to the Board of Directors of TVA;

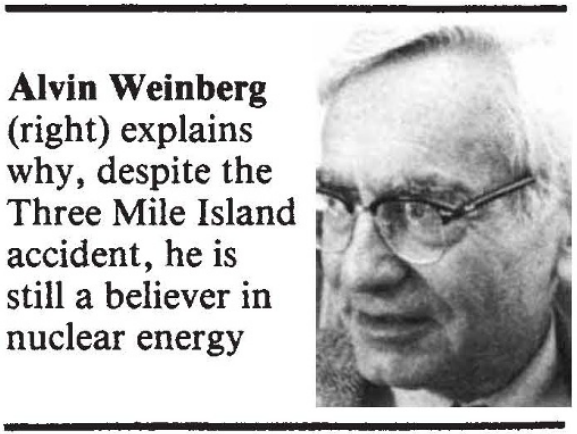

- the professionalisation of the cadre operating nuclear reactors - operators will receive training equivalent to a bachelor's degree, and salaries high enough to attract and keep the best, even though this places them at an advantage as compared to operators of fossil fuel or hydroelectric plants;

- more extensive plans for evacuation, and for keeping the public informed on the status of its nuclear plants.

In addition to these institutional changes, TVA is, on its own, proposing a number of technical improvements for its reactors that go beyond what the Nuclear Regulatory Commission requires. TVA, being the largest American utility, is well equipped to analyse and then implement safety mesures that a smaller utility might not be in position either to recognise or to pay for. It is to TVA's credit that one of its safety engineers, C. Michelson, had visualised essentially the Three Mile Island sequence a year before it actually happened, and had called the attention of Babcock and Wilcox, (the nuclear steam suppliers) and the Nuclear Regulatory Commission to the deficiency.

Although not mentioned in their plan, I would hope that TVA will confine future reactors to its existing seven sites rather than allowing nuclear sites to proliferate. The sites would be expected eventually to develop into powerful nuclear centres. They would be invested with a commitment of permanence: spent fuel elements, low level wastes, and decommissioned reactors could be stored for a long time on them.
After 100 years the high level wastes would be producing little heat and the low level wastes and reactors, though not innocuous, would be much easier to handle.

The TVA plan, together with confinement of the nuclear enterprise essentially to existing sites, seems to me to constitute an acceptable nuclear energy system. TVA, being large, self-contained, and able to set its own rates, is better able to implement such a policy than are most of the private utilities. But I believe the private utilities ought to move strongly in this direction by establishing nuclear generating consortia, perhaps like the Yankee Atomic Electric Company, in each of the nine regional Reliability Councils; or possibly by assigning generation of all nuclear energy in a region to a single utility that has the strength to take on this responsibility. Such a nuclear generating company, from the president down to the operators, would think, act, and know the nuclear business, with all its responsibilities and hazards.

Will an aggressive acceptance by the US, or even the whole world, of some version of the TVA plan plus confined siting and technical fixes, be enough to tide nuclear energy over the present disaffection? I certainly hope so. The TVA plan, with its standby mobilisation of experts to respond to any contingency, ought to give fullest opportunity for the exercise of human ingenuity. The serious nuclear accidents, though they were precipitated by human error, were contained by human ingenuity. At Three Mile Island, shutting off the high pressure injection pumps was perhaps the key operator error; but only 12 curies of ${ }^{113}$ I were released - some 2000 times less than was released at Windscale in 1958. A key manoeuvre in preventing more iodine from escaping was the replacement of the iodine filters a few days after the incident began. This was carried out faultlessly by experts from various nuclear installations.

I consider myself to be a not uncritical advocate of nuclear energy: an advocate because $I$ believe we need nuclear energy and the alternatives to it are faulted; not uncritical because I have been close to the technology for enough years to recognise its deficiencies. Despite Three Mile Island, I remain an advocate. Those who wish to extirpate nuclear energy base their position on an unquestioning acceptance of human fallibility and a cynical denial of human ingenuity. The two major accidents in the United States, Browns Ferry and Three Mile Island, suggest to me that this is an unjustifiably pessimistic assessment of the human condition. Rather, as the TVA Plan reveals, there is much room for creating institutions that will encourage ingenuity, and on which we can base an acceptable nuclear energy. 